\title{
Perceptions and Unmet Expectations of Undergraduate Students on the Role of Counselling in Academic Achievement: Implication for Academic Development Program Review
}

\author{
Patrick Okoh Iyeke ${ }^{1}$, Lucky Chukwunalu Onyema ${ }^{1} \&$ Ezekiel Uba Nwose ${ }^{2, *}$ \\ ${ }^{1}$ Institute of Education, Delta State University, Abraka, Nigeria \\ ${ }^{2}$ School of Community Health, Charles Sturt University, Orange NSW, Australia \\ *Correspondence: School of Community Health, Charles Sturt University, Orange, 346 Leeds Pde, Orange, NSW \\ 2800, Australia. Tel: 61-2-6365-7282. E-mail: enwose@csu.edu.au
}

Received: September 2, $2018 \quad$ Accepted: September 19, $2018 \quad$ Online Published: October 1, 2018

doi:10.5430/wje.v8n5p88

URL: https://doi.org/10.5430/wje.v8n5p88

\begin{abstract}
This study aimed at evaluating the perceptions of students about the role of counselling and unmet expectation of undergraduate students. The study adopted a descriptive survey design. The participants $(\mathrm{N}=150)$ recruited from first and second year students of Institute of Education in the University. Over $81 \%$ of students are aware of counselling services and affirm the relevance to academic achievement. However, $69 \%$ cannot affirm provision of roadshows to enhance awareness. The proportion of students disagreeing on provision of roadshows to enhance awareness may imply non-utilization of available academic development program and unmet counselling needs that calls for a review.
\end{abstract}

Keywords: academic achievement, academic development program, client perspective, counselling in higher education, roadshow advert

\section{Introduction}

Effective counselling programs for students are important in every school climate and constitute a crucial element in improving student achievement (Shaterloo \& Mohammadyari, 2011). Counselling is an integral part of education and a continuous service that must be purposively both generalized and specialized (Shallcross, 2012). However, to maintain a proper counselling service, the client's perception is essential. In the health sector, it has been acknowledge that clients' attitudes to counselling relate to a range of factors, chief among them being individual perception (Risenga \& Davhana-Maselesele, 2017).

This is an indication that student's perception of counselling roles is key to the program's long-term goals of helping to enhance academic achievement. As a matter of fact, if the perception of counseling is low or poor, it is likely to elicit negative response and result in a rejection of its programs. The opposite holds if their perception is high or good (Strowig \& Sheets, 1967). It is common knowledge that expectations and perceptions differ between individuals, which has been noted to apply in counselling (Thomas, 2017). It has also been suggested that expectations and perceptions may differ with an individual or group of individuals, hence there may be no correlation relationship between perception of counselors and satisfaction with counselling (Heppner \& Heesacker, 1983; Severinsen, 1966; Strowig \& Sheets, 1967). Given that counseling is a psychological process of helping an individual to achieve self-direction or target, the definition of such target lies between the client and counsellor (Thomas, 2017).

In this era of student extremism, buoyed by questionable information on the internet, there is increasing pressure on school counselors to justify their relevance, including the adequacy of their programs (Akinboye, 1980; Yuksel-Sahin, 2012). In Africa including Nigeria, it has been sufficed that practice of counselling and guidance is incomparable with the way the services are practised in the Western world; and part of the reasons experiences of the clients as well as differences in the facilitating environment (Goss \& Adebowale, 2014). Hence, it is safe to suggest that there may yet to be a model of evaluating the effectiveness of school counselling programs in Nigerian 
institutions of higher learning. In other words, there could be a gap between knowledge of students' perception of counselling services, and whether the school counselling clients have unmet expectations.

\subsection{Statement of the Problem}

Academic development involves academic and professional staff in strategic activities that enhance learning and teaching in universities (Hunt \& Chalmers, 2017). Counselling underpins the 'student support services' that have been adopted as an efficient academic mechanism all over the world. The primary purpose or business perspective may be student's retention and success, but the overreaching concept is to utilize interpersonal relationships to achieve students' academic development (Devi, Devaki, Madhavan, \& Saikumar, 2013). That is, there are various types of strategic supports rendered to enhance students' success (Midkiff \& Grinage, 2017), counselling is one such activities. In order to achieve the target of academic development, it is supposed to put student learning and experience at its core (Hunt \& Chalmers, 2017).

However, it has been indicated that the practice of counselling in Nigeria differs from the Western world due to several reasons that include facilitating environment and perception of the client (Goss \& Adebowale, 2014). In a University with an established department of counselling psychology, a functional school counseling program/service is in existence as expected, but whether the counselling service is being voluntarily advertised to, and sought after by the students are unknown. Further, given that academic development involves academic and professional staff (Hunt \& Chalmers, 2017), school counselling is supposed to involve the teachers (Lam \& Hui, 2010), and enhance the student-teacher relationship. Guided by the knowledge that students' perception and utilization of counselling services are under-researched (Gaughf, Smith, \& Williams, 2013), the perceptions of undergraduates regarding the role of counseling service and its perceived importance in their journey towards academic achievement vis-à-vis in achieving their academic development are also unknown.

\subsection{Research Questions}

1) Do students in the University see counselling service as relevant in enhancing effective study skills?

2) Do students in the University perceive counselling as necessary in developing effective examination behavior?

3) Is there any difference in the perception of male and female students on the relevance of counselling in academic performance?

4) Are the counselling services available in the University proactively advertised?

5) Are the counselling services available in the University improving student-teacher relationship?

\section{Methodology}

This study adopted a descriptive survey research design. The study population consisted of year one and year two undergraduate students of the Institute of Education in a University. A total of one hundred and fifty students $(\mathrm{N}=$ 150) were sampled using stratified sampling technique. The questionnaire used in collecting data include 16-questions excluding unidentifiable demographics information that constituted section A. Ten of the questions were on perception of relevance, which constituted section B. The other six questions surveyed the nature of services provided, including whether the counselling service providers were organizing roadshows to enhance awareness among students (Fig 1). In this study, roadshow is defined as meetings organized by counselling providers for the purpose of talking with client population or focus groups; both to create awareness and the palpate the clients' need.

The survey questions were formatted in table for responses to be on Likert scale, so that average score $>3$ was considered positive response. In addition, percentage of responses were also used for evaluation. Questions 1, 2, and 6 of questionnaire section B were used to answer research questions 1. Responses to B3 - B5 were analyzed to answer the second research questions. All questions were analyzed for third, while responses to C6 and B10 were analyzed for research questions fourth and fifth research questions, respectively. 


\section{RESEARCH INSTRUMENT}

Questionnaire on students' perception of counselling in academic achievement

Instruction: In each of the sections, please indicate your response against each statement by ticking in the appropriate column categorized into Strongly Agree (SA), Agree (A), Unsure (U), Disagree (D), and Strongly Disagree (SD). Do not mark more than one response for each statement. The purpose of the instrument is for research only. Therefore, feel free to respond honestly as all reaponses shall be kept highly confidential.

\section{SECTION A: Demographic data}

1) Sex: Female () Male ()

2) Age: 13-16 years () 17-20 years () 21 and above ()

3) Level: Year 1 () Year 2 ()

SECTION B: Perception on the relevance of counseling services
\begin{tabular}{|l|l|l|l|l|l|l|}
\hline \multirow{2}{*}{ ITEMS } & SA & A & U & D & SD \\
\hline & 4 & 3 & 2 & 1 & 0 \\
\hline 1 & I see CS as relevant in enhancing their study skills & & & & & \\
\hline 2 & CS have helped improve my study skills & & & & & \\
\hline 3 & I see CS as necessary in developing appropriate examination behavior & & & & & \\
\hline 4 & Effective counseling helps in reducing examination malpractice & & & & & \\
\hline 5 & Effective counseling helps me in good time management & & & & & \\
\hline 6 & CS has led to my improved academic performance & & & & & \\
\hline 7 & The female \& male DELSU students see CS differently & & & & & \\
\hline 8 & CS are more relevant for female students & & & & & \\
\hline 9 & CS are more relevant for male students & & & & & \\
\hline 10 & CS have led to better relationship with my lecturers & & & & & \\
\hline
\end{tabular}

Key. CS - counselling services

SECTION C: Nature of Counseling Services provided
\begin{tabular}{|l|l|l|l|l|l|l|}
\hline \multicolumn{2}{|l}{ ITEMS: DELSU counseling center... } & SA & A & U & D & SD \\
\hline & 4 & 3 & 2 & 1 & 0 \\
\hline 1 & Provides educational counseling & & & & & \\
\hline 2 & Provides personal-social counseling & & & & & \\
\hline 3 & Organizes orientation programs for new students & & & & & \\
\hline 4 & Organizes talk shows of educational nature* & & & & & \\
\hline 5 & Provides individual gervices for students with special needs & & & & & \\
\hline 6 & Organizes roadshows to enhance awareness among students & & & & & \\
\hline
\end{tabular}
* On effective study habits, time management, effective use of leisure, etc

Figure 1. The Questionnaire Survey Instrument

Descriptive statistics analysis performed were percentage frequencies and means to determine the perception of undergraduate students towards the role of guidance and counselling in academic achievement. MANOVA analysis was further carried out using SPSS version 11 to determine which factors were significantly important as regards the responses generated from the questionnaires. The demographic responses on 'section A' were rated for the subgroupings - viz:

- Gender groups: Female (1), and Male (2),

- Study level groups: Year One (1), and Year Two (2),

- Stratified age-groups: 13-16 years (1), 17-20 years (2), and 21 and above (3)

\section{Result}

The 150 respondents comprised 86 females and 64 males. The year one students were 85, with the remaining 65 in second year level. The stratified age-groups have 62,50 and 38 in the stratified age group $1^{\text {st }} \leq 16$ years old, $2^{\text {nd }} 17-$ 20 years old and $3^{\text {rd }} \geq 21$ years groups respectively. Thus, the average age of study participants is in the range $17-20$ years old; while a simple majority of the respondents are Year_1 students and females. Descriptive analysis of coded 
data indicate that perceptions were generally on the affirmative $(\mathrm{B} 1-\mathrm{B} 6$ : averages $\approx 3$ ), except for questions bordering on gender and student-lecturer relationship (B7 - B10: averages $<2.0)$ (Table 1).

Table 1. Descriptive Statistics of Responses ( $\mathrm{N}=150)$

\begin{tabular}{lllllll}
\hline & Mean & Median & Mode & SD & Skewness & C' $^{\prime}$ Level \\
\hline Age & 1.84 & 2.00 & 1.00 & 0.80 & 0.30 & 0.13 \\
Gender & 1.43 & 1.00 & 1.00 & 0.50 & 0.30 & 0.08 \\
S' Level & 1.44 & 1.00 & 1.00 & 0.51 & 0.40 & 0.08 \\
B1 & 3.53 & 4.00 & 4.00 & 0.76 & -2.54 & 0.12 \\
B2 & 3.26 & 3.00 & 4.00 & 1.00 & -1.85 & 0.16 \\
B3 & 3.15 & 3.00 & 3.00 & 0.92 & -1.65 & 0.15 \\
B4 & 2.70 & 3.00 & 3.00 & 1.26 & -0.87 & 0.20 \\
B5 & 2.88 & 3.00 & 3.00 & 1.21 & -1.18 & 0.20 \\
B6 & 2.53 & 3.00 & 3.00 & 1.34 & -0.54 & 0.22 \\
B7 & 1.85 & 1.00 & 1.00 & 1.45 & 0.15 & 0.23 \\
B8 & 1.83 & 1.00 & 1.00 & 1.39 & 0.28 & 0.22 \\
B9 & 1.53 & 1.00 & 1.00 & 1.34 & 0.56 & 0.22 \\
B10 & 1.61 & 1.00 & 0.00 & 1.61 & 0.38 & 0.26 \\
C1 & 3.10 & 3.00 & 4.00 & 1.16 & -1.44 & 0.19 \\
C2 & 2.82 & 3.00 & 3.00 & 1.20 & -1.19 & 0.19 \\
C3 & 2.94 & 3.00 & 3.00 & 1.21 & -1.26 & 0.20 \\
C4 & 2.29 & 3.00 & 3.00 & 1.45 & -0.38 & 0.23 \\
C5 & 1.92 & 1.00 & 1.00 & 1.42 & 0.23 & 0.23 \\
C6 & 1.35 & 1.00 & 0.00 & 1.48 & 0.69 & 0.24 \\
\hline Keys: C' & & & & & & \\
\hline
\end{tabular}

Keys: C' level: confidence level at 95\%; SD: standard deviation; S' Level - students' study level

On analysis whether students of the University see counselling service as relevant in enhancing effective study skills; responses to questions $\mathrm{B} 1, \mathrm{~B} 2$, and $\mathrm{B} 6$ on the questionnaire which are $3.53,3.26$, and 2.53 strongly suggests that on average students see counseling service as relevant in enhancing effective student skills (Table 1). Alternative evaluation in terms of percentage frequency of responses show amongst others that over $91 \%$ affirm the relevance of counselling to enhance their study skills and academic achievement (Table 2).

Table 2. Frequency of Responses Indicating Agreement to Each Question

\begin{tabular}{clll}
\hline SN & Questions & Agreed & $\%$ \\
\hline B1 & I see CS as relevant in enhancing their study skills & 145 & 97 \\
B2 & CS have helped improve my study skills & 136 & 91 \\
B3 & I see CS as necessary in developing appropriate examination behavior & 136 & 91 \\
B4 & Effective counseling helps in reducing examination malpractice & 112 & 75 \\
B5 & Effective counseling helps me in good time management & 121 & 81 \\
B6 & CS has led to my improved academic performance & 100 & 67 \\
B7 & The female \& male DELSU students see CS differently & 68 & 45 \\
B8 & CS are more relevant for female students & 63 & 42 \\
B9 & CS are more relevant for male students & 50 & 33 \\
B10 & CS have led to better relationship with my lecturers & 60 & 40 \\
C1 & Provides educational counseling & 127 & 85 \\
C2 & Provides personal-social counseling & 121 & 81 \\
C3 & Organizes orientation programs for new students & 123 & 82 \\
C4 & Organizes talk shows of educational nature* & 91 & 61 \\
C5 & Provides individual services for students with special needs & 66 & 44 \\
C6 & Organizes roadshows to enhance awareness among students & 47 & 31 \\
\hline
\end{tabular}

CS: counselling services 
On evaluation of the $2^{\text {nd }}$ research question on how students "perceive counselling as necessary in developing effective examination behavior", result shows $\geq 75 \%$ of the respondents agreed that counselling effectives (Fig 2). The analysis of data for the $3^{\text {rd }}$ research question involved all questions in the questionnaire - i.e. evaluation of differences between groups, result show variability in the questions where statistical significance is achieved. While significant differences in response to questions B10, C1, C2 and C6 are common to age and study level groups; C3 is common to study level and gender groups (Fig 3).

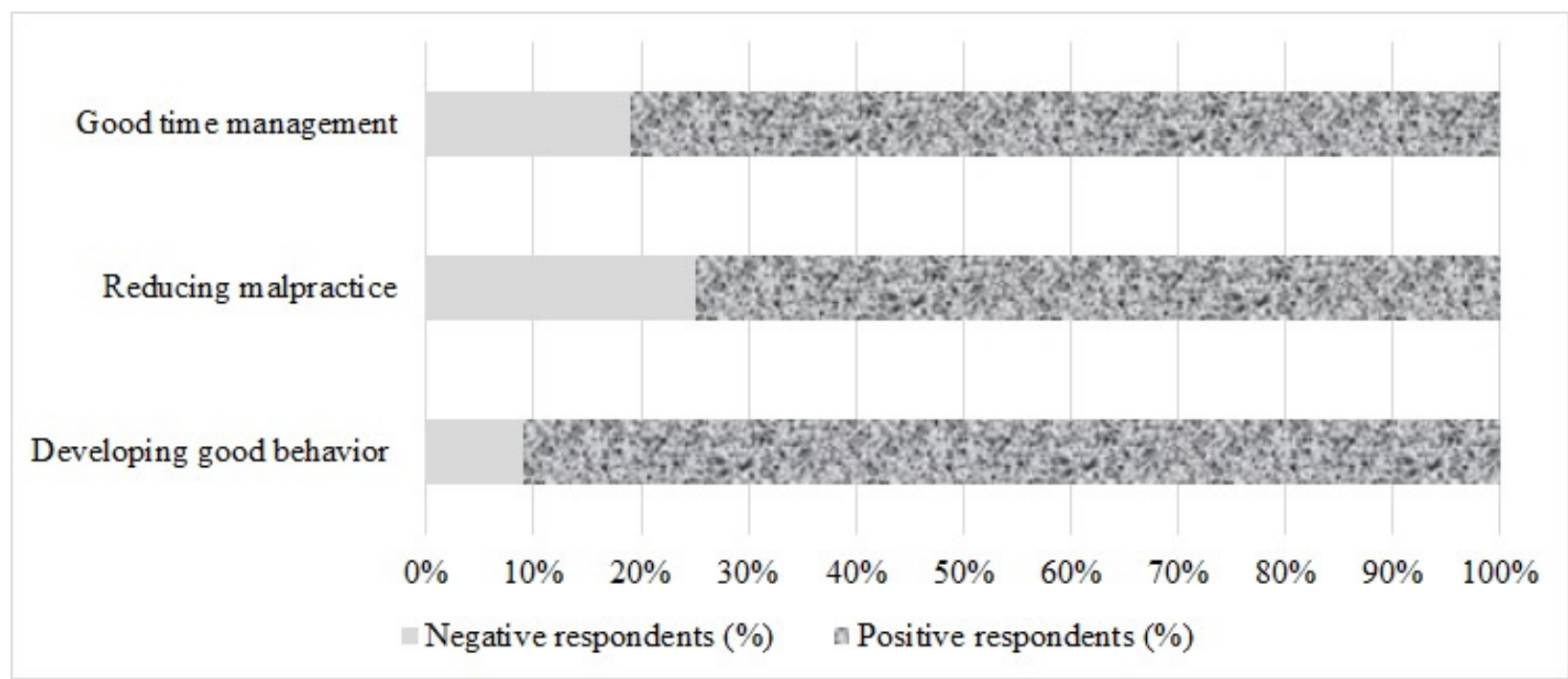

Figure 2. Perception of Counselling Effectiveness on Examination Behavior

Specific on provision of roadshows - i.e. the $4^{\text {th }}$ research question, the mean value of responses to question C6 is 1.35, which indicates that the respondents disagree that the counselling center provides roadshows to enhance awareness among students. In terms of proportion, only 31\% agree that the Counselling Centre in the university organizes roadshows (Table 2). MANOVA analysis on responses to question about roadshows, oldest students, by age and study level, are significantly unsure that roadshows are being organized, relative to other groups being emphatic disagreement (Fig 3; C6). Further MANOVA for evaluation of 'perceptions of unmet expectations' based on research question 5, MANOVA further shows significant differences in response to questions B10, C1, and C2 are common to age and study level groups, but not between gender groups $(\mathrm{p}<0.05)$. The significant affirmative response to 'better relationship with lecturers' is not corroborated by the responses to the questions on provision of educational and personal-social counselling (Fig 3).

\section{Discussion}

As indicated on the statement of the problem, this study is based on the principle that academic development involves both the teaching and non-teaching (i.e. academic and professional) staff in strategic activities that enhance learning vis-a-vis put students' perspective at its core. It is a given that counselling is one of such strategies. The study had set out to investigate whether students in the University perceive counselling service as relevant in achieving academic development; and if there is any difference in the perceptions of age, gender or study level groups. Further inquiry was to determine whether the counselling services available in the University are proactively advertised by roadshows; and improving student-teacher relationship. The observations from this study indicate that the students perceive counselling services as relevant in enhancing their effective study skills. Responses to questions $\mathrm{B} 1-\mathrm{B} 6$ and $\mathrm{C} 1-\mathrm{C} 4$ on the questionnaire are approximately 3 or higher (Table 1), which suggest that more than average of the students are aware and perceive counselling service as relevant in enhancing effective student skills. Most of the participants agree that the University's counselling center provides educational services, personal social services, and organizes orientation programs for new students (Table 2). However, the mean value of responses to question $\mathrm{C} 6$ is 1.35 , which indicates that on average, respondents disagree that the counselling center is making use of roadshows to advertise their services in order to enhance clients' awareness. Thus, there are positive and negative highlights to the research questions. 
First, the results indicate that students have a general high and positive perception on the role of counselling in academic achievement (Table 1). This slightly differs from the results shown by the study conducted at another Nigerian University that indicated a general low perception and all the variables except gender were found to be significant factors (Agi, 2014). The results of this study show differences between age groups, and that gender may be a significant factor that could influence some of the students' perception as indicated on the MANOVA analysis in $\mathrm{B} 6$ and $\mathrm{C} 3$ (Fig 2).

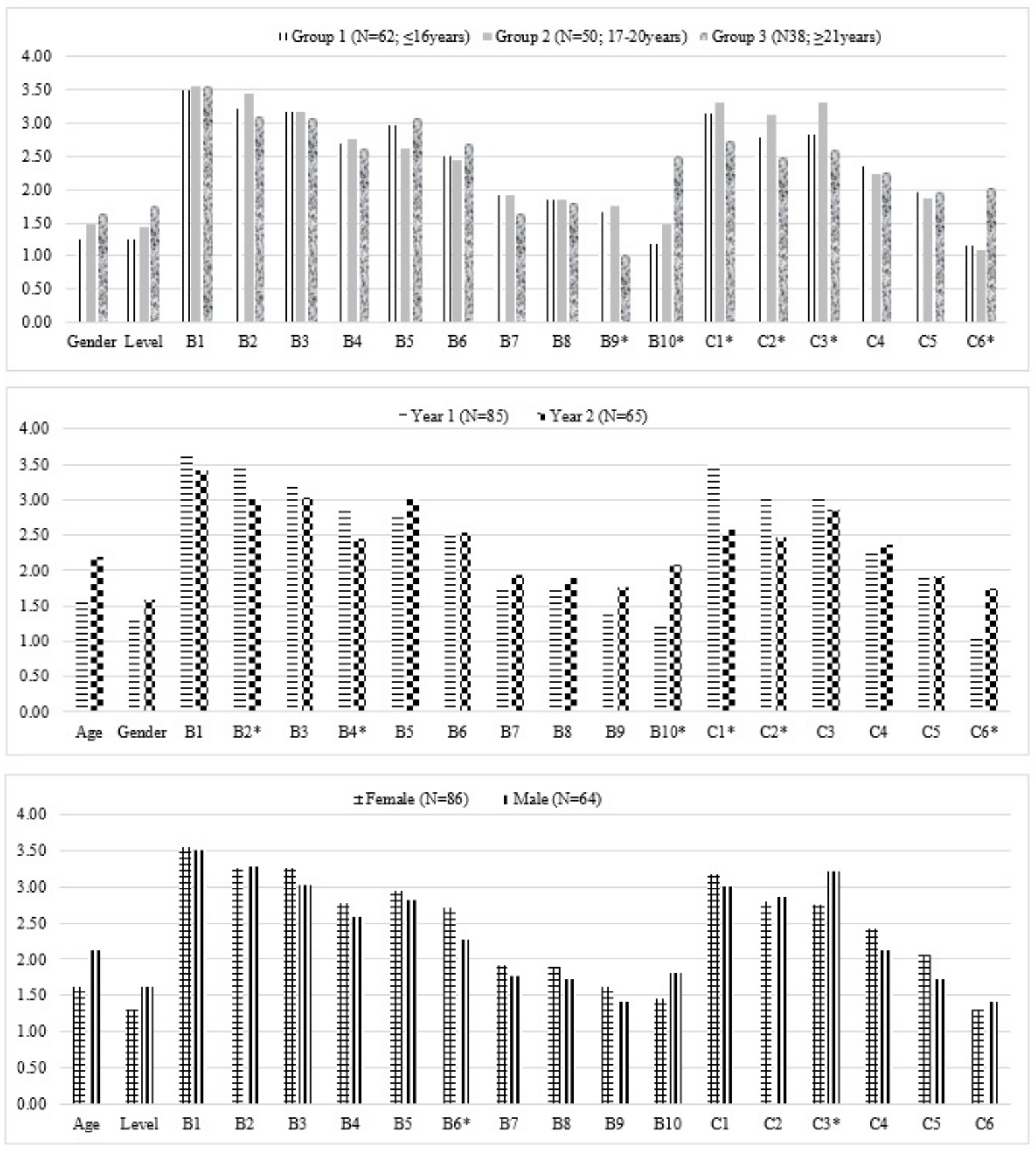

Figure 3. Comparison of Responses between Groups $(* \mathrm{p}<0.05)$

Second, the mean values of responses to questions B1, B2, and B6 on the questionnaire, which are approximately 3 or higher strongly suggests that on average the students see counselling service as relevant in enhancing effective study skills. Third, the MANOVA analysis shows that there is no significant difference to the responses of question 
B1 whether in Age, Gender, or study level. This affirms that the students unanimously agree that counseling services are relevant in enhancing their study skills. Regarding whether the students perceive counseling as necessary in developing effective examination behavior, descriptive statistics show mean values of responses to questions B3, B4, and $\mathrm{B} 5$ to be approximately 3 . That is, on average the students also agree that counselling is necessary in developing effective examination behavior (Fig 2).

Nevertheless, the fourth is negative. The findings show that the students disagreed that the counselling center organizes roadshows to enhance awareness of available services. On average, the $2^{\text {nd }}$ year students appeared unsure, but the $1^{\text {st }}$ year students' cohort significantly differed and really disagreed that there is any roadshow. Also, the oldest age-group appear to be unsure, while the others significantly disagreed. Both averages for female and male cohorts also disagreed (Fig 3). This could be translated to mean two things - viz:

- Firstly, some (31\%) of the students are aware of roadshows as part of counselling centre activities. The implication is that the rest majority of students are just unaware.

- Secondly, $69 \%$ may be unaware and missing out on services being the counselling centre personnel, which would feedforward to clients' unmet needs.

This is a critical finding worthy of emphasis - i.e. that $69 \%$ students are unsure if the University Counselling center provides roadshows and talk shows of educational nature, and individual counseling for students with special needs. Recent study from Zimbabwe has indicated that students are aware of the availability of counselling services, but never benefitted from it. In particular, the report indicated gender differences on different conditions (Nkoma, Zirima, Mudhovozi, \& Zhou, 2017). Yet, there is knowledge of gender-bias among counsellors, which had necessitated the call for training (Auwarter \& Aruguete, 2008). It is important to note that knowledge of this bias may constitute a barrier to some students seeking the available services. Further, distance from the counselling center as well as stereotyping have been identified as potential factors that determine whether the students will utilize the service (Pickles et al., 2012). What these imply is that school counsellors such as in the universities need to review if their target clients are well reached. Perhaps, the academic development programs need to be reviewed.

Fifth and lastly, is the focus on academic success. In this study, only 60/150 (40\%) respondents to 'question B10' agreed that counselling services improved their student-lecturer relationship. That is, $60 \%$ of the participants indicate that counselling services have not improved their relationships with the lecturers (Table 2). It is known that academic success largely depends on students' engagement with their lecturers (Abdel Meguid \& Collins, 2017; Schmidt, Wagener, Smeets, Keemink, \& van der Molen, 2015; Shernof et al., 2017). Therefore, this $60 \%$ of the respondents represents unmet expectations, which also constitute a clientele that should necessitate improvement academic development program of counselling services.

It is pertinent to restate the fact that academic development involves both academic and professional staff working together in strategic activities to enhance learning and teaching in universities (Hunt \& Chalmers, 2017). The implication is that there is an obvious gap in knowledge and practice. Both non-teaching counsellors and the lecturers need to review the services available to improve their student-lecturer relationship - i.e. in the pursuit of enhancing the students' academic success. So far from this study, over $91 \%$ believe in counselling services for academic achievement, but less than half of the believers have seen improvement attributable to counselling. This is a real indication of unmet expectation. This is quite important as unmet expectations can affect both client and the consultant equally, especially causing the client's development of a negative perception about the consultant's services (Bell, Kravitz, Thom, Krupat, \& Azari, 2002).

Further, in the context of 'knowledge, attitude and practice' gap, there is understanding that counselling in Africa is not as practiced in the Western world. We report high level of awareness of counselling services and the relevance to academic achievement. Nevertheless, majority of the survey population disagree on provision of roadshows to enhance awareness, implies much proportion of clientele not utilizing needed services that are available. This constitutes a gap between availability and awareness of services underlying unmet needs, which could be bridged by providers improving their awareness campaign.

\section{Conclusion}

The research findings indicate that the University students have a high level of insight on the relevance of counselling in academic achievement. However, there is a cloud of hesitation among respondents as to whether the counselling center provides individual counselling services for students with special needs. There appears to be significant difference in the level of awareness of available academic development program of counselling between 
stratified age-groups and study level subgroups. The $1^{\text {st }}$ year and younger age-group students disagree that such services exist; while the $2^{\text {nd }}$ and older students are unsure. It may benefit for University's counselling providers and lecturers to review their academic development program, with a view to improve awareness and erase elements of uncertainty among the students of the Institution.

\section{Declaration of interest statement}

Authors have no conflict or financial interest to declare

\section{References}

Abdel Meguid, E., \& Collins, M. (2017). Students' perceptions of lecturing approaches: traditional versus interactive teaching. Advances in Medical Education and Practice, 8, 229-241. http:/dx.doi.org/10.2147/AMEP.S131851

Agi, C. W. (2014). Evaluation of students' perception of school counselling and their attitudes toward its programmes. Arabian Journal of Business and Management Review (Nigerian Chapter), 2(5), 103-110.

Akinboye, J. O. (1980). Evaluation of the extent and effectiveness of counselling programs in Oyo and Ogun state secondary schools. Studies in Educational Evaluation, 6(2), 211-215. https://doi.org/10.1016/0191-491X(80)90023-1

Auwarter, A. E., \& Aruguete, M. S. (2008). Counselor perceptions of students who vary in gender and socioeconomic status. Social Psychology of Education, 11(4), 389-395. http:/dx.doi.org/10.1007/s11218-008-9056-0

Bell, R. A., Kravitz, R. L., Thom, D., Krupat, E., \& Azari, R. (2002). Unmet expectations for care and the patient-physician relationship. Journal of General Internal Medicine, 17(11), 817-824. https://doi.org/10.1046/j.1525-1497.2002.10319.x

Devi, M. R. R., Devaki, P. R., Madhavan, M., \& Saikumar, P. (2013). The effect of counselling on the academic performance of college students. $J$ Clin Diagn Res, $7(6), \quad$ 1086-1088. https://doi.org/10.7860/jcdr/2013/5247.3054

Gaughf, N. W., Smith, P. L., \& Williams, D. A. (2013). Faculty and student perceptions of academic counselling services at an academic health science center. Perspect Med Educ, 2(3), 165-170. https://doi.org/10.1007/s40037-013-0056-1

Goss, S., \& Adebowale, O. (2014). Counselling and guidance in Africa. British Journal of Guidance \& Counselling, 42(4), 353-358. https://doi.org/10.1080/03069885.2014.918363

Heppner, P. P., \& Heesacker, M. (1983). Perceived counselor characteristics, client expectations, and client satisfaction with counseling. Journal of Counseling Psychology, 30(1), 31-39. http://dx.doi.org/10.1037/0022-0167.1030.1031.1031

Hunt, L., \& Chalmers, D. (2017). Change Leadership, Management and Strategies to Promote Quality University Teaching and Learning. In Handbook of Research on Administration, Policy, and Leadership in Higher Education: IGI Global. https://doi.org/10.4018/978-1-5225-0672-0.ch015

Lam, S. K. Y., \& Hui, E. K. P. (2010). Factors affecting the involvement of teachers in guidance and counselling as a whole-school approach. British Journal of Guidance \& Counselling, 38(2), 219-234. https://doi.org/10.1080/03069881003674962

Midkiff, B., \& Grinage, L. (2017). A Typology of Supports for First Generation College Students in the U.S.: The Role of Leadership and Collaboration. In Handbook of Research on Administration, Policy, and Leadership in Higher Education: IGI Global. https://doi.org/10.4018/978-1-5225-0672-0.ch014

Nkoma, E., Zirima, H., Mudhovozi, P., \& Zhou, C. (2017). Gender differences in students' perceptions of school guidance and counselling services in Mberengwa District, Zimbabwe. Zimbabwe Journal of Educational Research, 29(2). https://www.ajol.info/index.php/zjer/article/view/159469

Pickles, K. J., Rhind, S. M., Miller, R., Jackson, S., Allister, R., Philp, J., . . Mellanby, R. J. (2012). Potential barriers to veterinary student access to counselling and other support systems: perceptions of staff and students at a UK veterinary school. Vet Rec, 170(5), 124. https://doi.org/10.1136/vr.100179

Risenga, P. R., \& Davhana-Maselesele, M. (2017). A concept analysis of young adults; Perception of HIV 
Counselling and Testing. Health SA Gesondheid, 22, 213-220. https://doi.org/10.1016/j.hsag.2017.01.007

Schmidt, H. G., Wagener, S. L., Smeets, G. A. C. M., Keemink, L. M., \& van der Molen, H. T. (2015). On the use and misuse of lectures in higher education. Health Professions Education, 1(1), 12-18. https://doi.org/10.1016/j.hpe.2015.11.010

Severinsen, K. N. (1966). Client expectation and perception of the counselor's role and their relationship to client satisfaction. Journal of Counseling Psychology, 13(1), 109-113. http://dx.doi.org/110.1037/h0023064.

Shallcross, L. (2012). Specialist, generalist or niche provider? Counselling Today. Retrieved May 1, 2012 from https://ct.counseling.org/2012/05/specialist-generalist-or-niche-provider/

Shaterloo, A., \& Mohammadyari, G. (2011). Students counselling and academic achievement. Procedia - Social and Behavioral Sciences, 30(2011), 625-628. https://doi.org/10.1016/j.sbspro.2011.10.121

Shernof, D. J., Ruzek, E. A., Sannella, A. J., Schorr, R. Y., Sanchez-Wall, L., \& Bressler, D. M. (2017). Student engagement as a general factor of classroom experience: Associations with student practices and educational outcomes in a university gateway course. Front Psychol, 8, 994. https://doi.org/10.3389/fpsyg.2017.00994

Strowig, R. W., \& Sheets, S. E. (1967). Student perception of counselor role. Personnel and Guidance Journal, 45(9), 926-931. https://doi.org/910.1002/j.2164-4918.1967.tb04813.x.

Thomas, B. (2017). What are the goals of counseling? Retrieved from https://owlcation.com/social-sciences/What-are-the-goals-of-counseling

Yuksel-Sahin, F. (2012). School counselors' assessment of the psychological counseling and guidance services they offer at their schools. Procedia-Social and Behavioral Sciences, 47(2012), 327-339. https://doi.org/10.1016/j.sbspro.2012.06.659 